\title{
Investigation of Metallic Silver Nanoparticles through UV-Vis and Optical Micrograph Techniques
}

\author{
Shujahadeen B. Aziz ${ }^{1}$, Omed Gh. Abdullah ${ }^{1, *}$, Dlear R. Saber ${ }^{l}$, Mariwan A. Rasheed ${ }^{2}$, Hameed M. \\ Ahmed $^{1}$ \\ ${ }^{1}$ Advanced Materials Research Lab., Department of Physics, College of Science, University of \\ Sulaimani, Qlyasan Street, Sulaimani, Kurdistan Regional Government-Iraq \\ ${ }^{2}$ Development Center for Research and Training (DCRT), University of Human Development, Qrga \\ Street, Sulaimani, Kurdistan Regional Government-Iraq. \\ *E-mail: omed.abdullah@univsul.edu.iq
}

doi: $10.20964 / 2017.01 .22$

Received: 6 September 2016 / Accepted: 29 October 2016 / Published: 12 December 2016

In this work, UV-Vis and optical micrograph techniques were used to characterize the reduced silver nanoparticles in chitosan polymer doped with $\mathrm{AgNO}_{3}$ salt. The UV-Vis spectrum shows distinguishable surface plasmonic resonance (SPR) absorption peaks at about $430 \mathrm{~nm}$ for the samples containing different amount of silver salt. The SPR peaks indicate the existence of silver nanoparticles. Upon the increase of silver nitrate salt concentration, the SPR peak intensity is enhanced, indicating the reduction of large amount of silver ions to the metallic silver nanoparticles in chitosan (CS) host polymer. Optical micrograph results show that silver nanoparticles are well dispersed at low silver salt concentrations. A leakage of large white spots of silver nanoparticles was observed at a higher silver salt concentration. The effect of lattice energy of silver salts on silver ion reduction and its distribution is interpreted. The FE-SEM image shows small white spots of silver nanoparticles on the surface of the sample. The observed shift in the Fourier transform infrared (FTIR) bands of $\mathrm{CS}: \mathrm{AgNO}_{3}$ relative to that of pure CS indicates the complexation between the chitosan polymer and the silver nitrate salt.

Keywords: natural polymers electrolyte; UV-Vis; Optical micrographs; SEM; FTIR

\section{FULL TEXT}

(C) 2017 The Authors. Published by ESG (www.electrochemsci.org). This article is an open access article distributed under the terms and conditions of the Creative Commons Attribution license (http://creativecommons.org/licenses/by/4.0/). 